\title{
A Study of Autonomy English Learning on the Internet
}

\author{
Yunsheng Zhong \\ Foreign Language Department of Qinzhou University \\ Qinzhou 535000, China
}

\begin{abstract}
With the variety of environment and method of English learning, Autonomy English learning on the Internet is playing a more and more important role in modern English learning. It challenges the traditional learning approach, and also is forwardness. This paper points out that autonomy English learning on the Internet facilitates the improvement of the English level even more on the basis of the author's acquisition and experience, as well as explains the favorable factors and unfavorable factors of autonomy English learning on the Internet, suggesting the effective strategies of autonomy English learning on the Internet.
\end{abstract}

Keywords: Autonomy English learning, Internet, Virtual English environment

\section{Introduction}

Nowadays, quality-oriented education has become the ultimate goal of our education. The core of English learning has shifted to how to develop the ability of autonomy learning anytime and anywhere. The application of internet technology has developed a new field for autonomy English learning which is becoming more and more popular at home and abroad. Learning English on the Internet can create efficient and high-quality achievement in personal or mass English learning. More and more people start to pay attention to it and study how to make a full use of it.

English learning needs an English environment, but we cannot always communicate with the native speakers of English face to face. What teaching of traditional English adopted is one-way teaching mode from teacher to student, which violates the essence of language teaching that is cultivating students' language communication competence. Now, we could say that the Internet shrinks and bridges the distance between the people of the world in space, and makes a globalized communicational stage. The way using the Internet to learn English can compensate for the lack of general approach with no real English environment, which will greatly enhance English autonomy learning.

However, in China, it's not universal that English learners use the Internet to autonomy English learning. The efficiency of learning is low, the result is not satisfactory. What are the reasons and how to deal well with the permanent approach for the ideal goal of autonomy English learning is a must to seek for the resolution.

\section{Favorable factors of autonomy English learning on the Internet}

Autonomy English learning on the Internet is one of the most important learning approaches which mostly reflects the main part and individual-orientation of students' study. According to one's conditions, a person can choose the learning materials, methods and the depth of study; arrange study on one's own schedule. As we all know, different people have different background knowledge, study ability and cognitive ability on study. In class, teachers always have no time to focus on the different acceptance specially. So, there is not efficient. While it is extremely different in the approach of autonomy English learning on the Internet, which always offers the great initiative on study, rich variety of choices, typical individual character of study, notional flexibility for arrangement and pleased dynamic interaction. Of course, there are some relatively unfavorable factors of autonomy English learning on the Internet, for example, appearing poor ability of learner's autonomy English learning, negative impact of English learning motivation and other external environmental impact. It is a considerable issue to find the resolution to overcoming how to approach the former and avoid the latter. All in all, autonomy English learning on the Internet depends on the learners' internal factors. Adding to teachers' supervision, assistance and guidance, the subjective willing of the learners is the key to the goal of learning English on the Internet well.

\section{Requirements for efficiency of autonomy English learning on the Internet}

\subsection{Promoting self- monitoring ability}

Self-monitoring ability is to play full the enthusiasm of learners and the initiative of learning, and gives the main body of individual the fundamental recognition. The self-monitoring level of students is the key factor to success in autonomy English learning in the relatively free-loose Internet environment. The Cognitive Constructivism School believed that autonomy learning was actually the learning of cognitive monitoring, and the process that students 
actively adjust learning strategies and effort based on their learning abilities and learning tasks. Learning strategies mean the various actions and steps students take in order to effectively study and develop themselves.

In order to really realize promoting self-monitoring ability, the followings are additional. First, learners should establish a good learning goal. Second, learners should formulate feasible study plan. Third, learners should optimize the self-evaluation for his learning process, confidence and effects.

\subsection{Strengthening cooperation}

In the situation of all mass organizations, random and disorder, which easily lead to "information Trek" and "information overload", and at the isolation between students and teachers, which always leads the role of teacher and teaching management weakening at learning on the Internet, it is very practical for the present learners to strengthen and develop the strong awareness of cooperation among the mass of autonomy English learners on the Internet. Most students in the personal autonomy English learning on the Internet are generally lack of stamina. The development of autonomy English learning ability on the Internet should not be blindly optimistic. First all, they need realize that fact that teachers are the most direct and important guide, partners and supervisors for providing a good environment, helping students strengthen their autonomy consciousness and develop independent learning behaviors, so as to enhance the capacity of autonomy learning, specifically to manifest in learning strategies, to ensure the implementation of the plan, to build a learning platform for students and timely to provide students with the necessary knowledge, skills and many other help; to direct students formulate learning goals, to encourage more cooperation between the learner groups and supervise the realization of self-evaluation

\subsection{Optimizing of network configuration}

There are many elements to influence the quality of English learning network, such as, the restriction of builders' purpose, foreign languages level, technology. As well as, the laws and regulations to protect the copyright of network is imperfect at present. The contents of the website are seriously challenged. We should establish a sense of innovation and appeal to professionals joining in the building of websites for the stabile team of building sites. Sites builders' occupation, education philosophy, English degree, the level of modern educational technology, and interest can influence the quality of websites. Voices of English as an example: because site builders are experts of foreign language teaching and network education, its website has these advantages: positioning clear, distinctive features, abundant resources, rational design and high interactive. Excellent English language learning websites should reflect the advanced teaching philosophy. The development of English-language websites ultimately depends on English educators of their own efforts.

English teachers are familiar with the teaching and learning process and education regulation that should become the major force of the construction of sites. Measures should be taken to guide and encourage English teachers learning multimedia and network technology, and actively participate in the construction of English learning websites, so that they can establish a number of high-quality sites to meet the growing demands of English learners and promote network process of China's English Learning. At the same time, we should encourage dialogues between English teachers and computer or network professional and technical personnel to cooperate in the development of sites, in order to form a specialized and diversified construction site team for the whole soul and heart to serve the learner on Internet.

\section{Approaches of autonomy English learning on Internet}

\subsection{English learning website}

As we all know, the content and knowledge in class are limited, and are impractical. The application of Internet technology has greatly broken the limitations of space and time in class. Autonomy English learning on the Internet can spread the knowledge from in class to out of class. Of course, websites cannot take the place of library, but it has its own special functions while the library has not, such as, speed of search, immediate information, etc. Some sites provide large amount of English language learning and information, such as listening, speaking, reading, writing, grammar, testing, and background knowledge. That information, including some audio and visual information can be downloaded. It has been recommended two foreign English language learning websites as following:

1) http://eleaston.com/english.html

2) http://www.eslcafe.com/

If you want to visit more pages, you can use the search engine, such as: Yahoo. You can type: "TESL", "ESL", "TEFL", "EFL", "English learning"," English Study", or "Distance learning", you will get what you want.

\subsection{English learning magazine}

There are many free English learning magazines and regular e-mail about English learning for you on the Internet. Now here are several free e-mail magazines. Firstly, you can send an email to this address: vu47-request@burger.forfree.com. On the body of letter, you only need write: subscribe vu47 and your e-mail address. You will receive an email on 
English vocabulary, phrases and syntax every week. Secondly, you can send an email to this address: trivia@mailbits.com. You will receive a daily e-mail to give an explanation or tell stories and dubious origin for a word of English and a form of expression. Thirdly, you can send an email to this address: up-to-date-idioms-subscribe@ onelist.co m. You will receive an e-mail each working day. They teach you an American idiom each time, and give out an explanation and an example. Fourthly, domestic free e-mail magazine, "English Zone". Please send e-mail to the address: list@soim.com. Theme written: subscribe English. You will receive three English learning e-mails every week.

\subsection{English Learning Discussion Group by E-mail}

It's a more economic way to subscribe by e-mail. There are many English learning discussion groups on the Internet, such as, the intensive English forum, science and technology English forum, the English Writing forum and teaching discussion forum. I recommend three abroad discussion groups. 1) "English writing forum": you should send an email to the address: listerv@listserv.net . You should write "SUBSCRIBE ECOMP-L" on letter body. 2) "English learning lover": you should send an email to the address: Majordomo@coe.Missouri.edu. Besides, you should write "subscribe English-L" on letter body. 3) "BBC": you should send an email to the address: Majordomo@listserv.bbc.uk and you should write "subscribe BBC-ELT" on letter body.

There are different methods to subscribe to the different thematic discussion groups. Generally speaking, when one sends these e-mails to reserve some topics of discussion groups, will receive two letters. One is that you have been notified to accede to the forum; the other is to introduce something about it, such as the aims, using method, managers and competent units of the name and address. Some enable you to reply upon its requirements, and some let you read the group's charter and regulations. After agreement, you have to reply a signed e-mail to two important addresses. One is sent to all members of topics discussion group, where you can ask questions or raise your points of view on the issues of others. If the group includes 1,000 people, all of them can see your issues and perspectives. The other is sent to the person in charge of the group. If you have any technical problems or you want to withdraw from this group, you can send an e-mail to this address with much care.

\subsection{English chat room}

In order to develop oral English, many people take oral class, chat with foreign teachers, or participate in English corners on campus. However, they still find it little effective. The key reason is that their confidence is not enough. And the next is their package of abundant practice.

Now, you can invite foreign teachers to your home and talk with native speakers anywhere and anytime. That makes the best use of the communication function of the Internet and brakes limitation of time and space. English chatting needs quick reflection. So, it's a very good promotion to virtual communication. Chatting on the Internet, you can understand different country's cultural connotation and background. Meanwhile, it can stimulate the interest in oral or write, and improve the level step by step. Now I recommend Yahoo chat rooms. When you enter into Yahoo website: http://events.yahoo.com/netevent/Chat_Rooms/, firstly you must conduct chat room registration, and then you will be requested to have a name and a password. Then, you must fill a number of other elements, such as: Address and e-mail address, etc. Finally, you can enter the chat room.

\subsection{Foreign pen pals on Internet}

We can communicate with foreign pen pals via e-mail on the Internet. There are several websites to making pen pals. In these pages, you can see the dating ads by people from various countries to make friends. you can choose to make your friends, or you could play your own Personal ads, soon you will receive the e-mail from your friends. I recommend three pen pal web sites:

1).http://www.wfi.fr/volterre/keypals.html

2). http://deil2.lang.uiuc.edu/penpals/

3) http://www.linguistic-funland.com/addapal.html

If you want to visit more friends' websites, you can search them through engines. You can type "pen pal" and "key pal", you will find more websites.

\subsection{Online electronic bulletin board system}

Electronic bulletin boards system (BBS) also is called 'forum'. We can participate in online electronic bulletin board system to English study and discussion. Electronic bulletin boards system like a big bulletin board, you can paste the issue of English learning to the above, and advocate the problems in the process of learning English. You can exchange of experience and discuss with your friends to find the best answer on it. Firstly, you have to conduct user registration in the relevant forums, such as the English forums of Sohu educational channel (http://learning.sohu.com/), and then enter into the bulletin board. If you want to visit more electronic bulletin board system, you can type "BBS" to conduct searches. 


\section{Conclusion}

We find the approach of autonomy English learning on the Internet is completely different from the traditional one. Learners obtain knowledge on the Internet instead of lonely dependence on teachers and books. Learning resources from the Internet not only are very colorful, but also multi-channeled, multi-perspective, multi-leveled and multi-formed. Moreover, it is very quick and timely. We can choose learning materials from the extensive resources we need on the Internet, thus which easily aroused keen interest in learning initiative.

It can fully move the initiative and enthusiasm and improve the learning efficiency. Although autonomy learning on the Internet can bring so much benefit and convenience to us, it's no enough to be used. If we really make the best use of it, our English learning will be expected and successful. Autonomy English learning on the Internet will be popular with everybody fully in the future. Everyone will develop and strengthen the ability of autonomy English learning on the Internet, so that we can acquire the skill of life-long learning to serve ourselves and the whole society better.

\section{References}

Fei Xie. (2002). Learning Autonomy and How to Train the Autonomy of Language Learning. Field of Foreign Studies, (6).

Hongmei Liu. (2005). A New Mode of Developing Students' Ability of Autonomy English Learning on the Internet. Teaching and Research, (10).

Li Tian \& Haiping Wu. (2007). A Probe of the Mode of Autonomy English Learning on the Internet. China's Adult Education (1).

Likun Zhang, etc. (2006). A Study of the Ability of Autonomy English Learning on the Internet. Teaching and Management, (8).

Pei Cai. (2007). On Autonomy College English Learning on the Internet. Journal of Innovation of China's Science and Education, (7).

Sanming Luo. (2004). On Learning English at the Age of Website. Beijing: Publishing House of Mechinical Industry, 7.

Shaokang Chen. (2005). How to Make Full Use of the Internet Sources of English Learning and Teaching. Journal of Shaoguan University, (1).

Weiqing Tang. (2006). Investigation and Research of Autonomy English Learning on the Internet. Thesis Collection of Journal of SunYah Shen University, (10). 